\title{
ANALISIS KELAYAKAN USAHATANI JAGUNG HIBRIDA PADA LAHAN KERING DI MERAUKE, PAPUA
}

\author{
Fransiskus Palobo*, Herman Masbaitubun, Siska Tirajoh \\ Balai Pengkajian Teknologi Pertanian Papua \\ Jl. Yahim Sentani - Jayapura Telp. (0967) 592179 Faks. 591235 \\ *Corresponding author: frans.merauke@gmail.com
}

\begin{abstract}
The success of agricultural development is very closely related to the technology used in agriculture. Good technology is the technology that is compatible with climate, varieties, agricultural and adaptive systems. Corn is still the second strategic commodity after rice because, in some areas, corn is still the second staple food after rice and also contributes to animal feed. This study aims to determine the economic feasibility of dryland corn farming through the application of technological innovations in the use of new improved varieties of hybrid corn seeds. The study was conducted in Karteb Village in Jagebob Subdistrict of Merauke Regency, from August to December 2017, the approach was carried out on land and outside agriculture with (1) the use of 4 (four) varieties of Bima 19 Hybrid URI, Bima 20 URI, NASA 29 and Bisi-2, (2) analyzing corn farm income using a balanced income and cost analysis. The results showed that the hybrid corn farm income in the URI Bima 19 variety; R/C 2.25, $B / C$ 1.25, breakeven production point $296 \mathrm{~kg} / \mathrm{ha}$, breakeven price IDR 2,273/kg and employee benefits IDR 237,233/day. Bima variety 20 URI and Nasa-29 variety $R / C$ value 3,18, B/C 2,18, break-even production point $249 \mathrm{~kg} / \mathrm{ha}$, break-even price $R p$ 1,783/kg and employee benefits IDR 420,767/day. Whereas the Bisi-2 variety; R/C 2.87, $B / C 1.87$, break-even production point $260 \mathrm{~kg} / \mathrm{ha}$, break-even price IDR 1.783/kg and employee benefits IDR 360.422/day
\end{abstract}

Keywords: hybrid maize, analysis of farming, feasibility, dry land, Рapua

\begin{abstract}
Abstrak : Suksesnya pembangunan pertanian sangat erat kaitannya dengan teknologi yang digunakan dalam berusahatani. Teknologi yang baik adalah teknologi yang mempunyai kesesuaian dengan iklim, varietas, sistem usahataninya dan adaptif. Komoditas Jagung sampai saat ini masih merupakan komoditi strategis kedua setelah padi karena di beberapa daerah, jagung masih merupakan bahan makanan pokok kedua setelah beras dan juga menyumbang untuk pakan ternak. Kajian ini bertujuan untuk mengetahui tingkat kelayakan ekonomi usahatani jagung dilahan kering melalui penerapan inovasi teknologi penggunaan benih varietas unggul baru jagung hibrida. Kajian dilakukan di Kampung Kartini Distrik Jagebob Kabupaten Merauke, sejak bulan Agustus sampai Desember 2017, metode pendekatan yang dilakukan secara on-farm dan off-farm dengan perlakuan (1) penggunaan 4 (empat) varietas Hibrida Bima 19 URI, Bima 20 URI, Nasa 29 dan Bisi-2, (2) menganalisis pendapatan usahatani jagung menggunakan analisis imbangan penerimaan dan biaya. Hasil Kajian menunjukkan bahwa pendapatan usahatani jagung hibrida varietas Bima 19 URI; R/C 2.25, B/C 1.25, titik impas produksi $296 \mathrm{~kg} / \mathrm{ha}$, titik impas harga $\mathrm{Rp}$ 2.273/kg dan imbalan kerja $\mathrm{Rp}$ 237.233/hari. Varietas Bima 20 URI dan varietas Nasa-29 Nilai R/C 3.18, B/C 2.18, titik impas produksi $249 \mathrm{~kg} / \mathrm{ha}$, titik impas harga $\mathrm{Rp} 1.783 / \mathrm{kg}$ dan imbalan kerja Rp.420.767/hari. Sedangkan varietas Bisi-2; R/C 2.87, B/C 1.87, titik impas produksi 260 kg/ha, titik impas harga Rp 1.783/kg dan imbalan kerja Rp 360.422/hari.
\end{abstract}

Kata Kunci : jagung hibrida, analisis kelayakan, usahatani, lahan kering, Papua 
Fransiskus P., Herman M., Siska T.: Analisis Kelayakan Usahatani ...

\section{PENDAHULUAN}

Kebutuhan jagung terus meningkat, baik untuk pangan dan pakan maupun sebagai bahan baku industri. Pada saat produksi dalam negeri tidak memadai, impor terpaksa dilakukan untuk memenuhi kebutuhan. Prospek budidaya jagung sangat baik, baik dari aspek harga jual maupun permintaan. Permintaan jagung dalam negeri cenderung meningkat dengan rata-rata pertumbuhan selama periode 2006-2015 sebesar 6,40 persen (BKPD Lampung, 2016). Meskipun rata-rata poduksi mengalami kenaikan sebesar 6,31 persen selama periode 2006-2015 (BPS, 2016), namun pada kenyataannya sampai tahun 2015, Indonesia belum mampu memenuhi permintaan jagung dalam negeri, terutama untuk industri pakan. Impor jagung tahun 2015 masih sebesar 3,267 juta ton (Pusat Data dan Informasi Kementerian Pertanian, 2016).

Suksesnya pembangunan pertanian sangat erat kaitannya dengan teknologi yang digunakan dalam berusahatani. Teknologi yang baik adalah teknologi yang mempunyai kesesuaian dengan iklim, varietas dan sistem usahataninya. Jagung sampai saat ini masih merupakan komoditi strategis kedua setelah padi karena di beberapa daerah, jagung masih merupakan bahan makanan pokok kedua setelah beras. Jagung juga mempunyai arti penting dalam pengembangan industri di Indonesia karena merupakan bahan baku untuk industri pangan maupun industri pakan ternak khusus pakan ayam. Dengan semakin berkembangnya industry pengolahan pangan di Indonesia maka kebutuhan akan jagung akan semakin meningkat pula.

Penyebaran penggunaan varietas jagung pada tahun 2002 adalah $28 \%$ hibrida, $47 \%$ komposit unggul, dan 25\% komposit lokal (Damardjati et al. 2005). Untuk mewujudkan Indonesia sebagai produsen jagung yang tangguh dan mandiri, strategi kebijakan diutamakan pada peningkatan produktivitas dengan memperluas penggunaan benih bermutu di tingkat petani yang direalisasikan melalui program pengembangan jagung komposit dan hibrida

Seiring perubahan lingkungan strategis dimana lahan pertanian semakin menyempit, anggaran Pemerintah semakin terbatas dan cekaman iklim semakin tidak menentu, maka upaya peningkatan produktivitas jagung melalui penggunaan benih varietas unggul merupakan salah satu upaya yang paling logis dalam meningkatkan produktivitas jagung. Dalam penelitiannya tentang: Analisis dinamika permintaan/konsumsi dan kebijakan pengembangan produkdi jagung nasional, Agustian, et al. (2014) mendapatkan hasil bahwa peningkatan produksi jagung memiliki peluang yang besar melalui: (1) Peningkatan produktivitas jagung dimana produktivitas potensial dengan semakin meningkatnya penggunaan varietas unggul hibrida, (2) Tercapainya peran swasta yang aktif dalam pengembangan industri benih, (3) Harga jagung yang semakin meningkat seiring dengan permintaan jagung yang semakin meningkat; (4) Dukungan Pemerintah Daerah dalam pengembangan jagung, dan (5) Masih memungkinnya perluasan areal pertanaman jagung pada lahan-lahan yang belum diusahakan dan yang belum dimanfaatkan secara optimal.

Untuk memacu peningkatan produktivitas ini diperlukan inovasi teknologi, diantaranya penggunaan varietas unggul baru (VUB) jagung hibrida yang mempunyai potensi hasil tinggi (Hosen, et al., 2013) dan sistem pengolahan tanah yang sesuai untuk wilayah tertentu (Atman, 2015). Kementerian Pertanian melalui Balitbangtan telah melepas puluhan varietas jagung, baik komposit maupun hibrida (Bahtiar et al., 2010). Di Indonesia, sejak tahun 1956 sampai 2013, telah ditemukan sebanyak 159 varietas jagung yang terdiri dari 38 varietas komposit dan 121 varietas hibrida. Varietas hibrida yang telah dilepas berasal dari Balitbangtan dan swasta. Diantara VUB hibrida yang dilepas oleh Balitbangtan adalah Bima-1, Bima-5, Bima-6, Bima-14 Batara, Bima-19 URI, sampai yang terbaru Bima-20 URI. Dari deskripsinya, potensi dan rata-rata hasil Bima-5 yaitu 11,40 t/ha dan 9,30 t/ha, Bima-6 yaitu 11,59 t/ha dan 9,36 t/ha, Bima-4 Batara yaitu 12,90 t/ha dan 10,10 t/ha, dan Bima-19 URI yaitu 12,50 t/ha dan 10,60 t/ha (Puslitbangtan, 2013).

Beberapa permasalahan teknis dan mendasar yang menjadi penyebab rendahnya produktivitas jagung antara lain seringnya terjadi gangguan iklim berupa stagnasi hujan pada periode pertumbuhan tanaman, kurangnya input yang digunakan petani, penggunaan benih 
yang kurang bermutu, dan sebagian besar petani menggunakan varietas hibrida hasil panen pada tahun sebelumnya (Wahid et al., 2006). Masalah sosial ekonomi juga ditemukan di lapangan, yaitu tingkat kegairahan petani masih rendah karena harga jagung yang sangat bervariasi dan tidak menentu (Taufik dan Thamrin, 2009). Selanjutnya Agustian (2012) melaporkan bahwa rendahnya produktivitas jagung di beberapa sentra produksi nasional disebabkan masih banyaknya petani yang menanam varietas lokal dan varietas unggul lama yang benihnya telah mengalami degradasi secara genetik dan belum dimurnikan. Benih yang ditanam adalah benih yang diambil dari pertanaman sebelumnya sehingga kemampuan produksinya terus menurun (Bahtiar et al., 2010). Oleh karena itu, upaya peningkatan produksi terus dilakukan melalui penggunaan benih varietas unggul baru yang berkualitas, teknologi pemupukan yang optimal serta upaya pengendalian hama dan penyakit. Kajian ini bertujuan untuk mengetahui tingkat kelayakan ekonomi usahatani jagung dilahan kering dengan penerapan inovasi penggunaan benih varietas unggul baru jagung hibrida.

\section{METODE PENELITIAN}

\section{Cakupan Kajian}

Kajian meliputi karakteristik wilayah dan usahatani jagung dalam satu musim tanam dengan membedakan usahatani jagung hibrida. Adapun jagung hibrida yang digunakan adalah varietas Bima 19 URI, Bima 20 URI, Nasa-29, Bisi-2 merupakan varietas jagung yang dihasilkan Balitbangtan. Khususnya untuk Jagung hibrida varietas Bisi-2 cukup banyak tersedia dipasaran dan sudah sering di tanam petani. Karakteristik wilayah yang ada dilihat dari berbagai sudut pandang, diantaranya topografi, iklim dan keadaan tanah. Sedangkan struktur analisis usahatani meliputi analisis pendapatan dan kelayakan.

\section{Lokasi dan Waktu}

Kajian dilaksanakan di kabupaten Merauke dan di pilih secara sengaja (purposive) sesuai dengan program strategis Kementrian Pertanian untuk dukungan inovasi teknologi di daerah perbatasan dengan membuat display demfarm dalam rangka mewujudkan lumbung pangan di kawasan perbatasan. Lokasi demfarm pada luasan 4 ha lahan kering Kampung Kartini, Distrik Jagebob Kabupaten Merauke. Wilayah pengembangan ini merupakan salah satu sentra pengembangan jagung di Kabupaten Merauke yang sesuai dengan CPCL Dinas Tanaman Pangan dan Hortikultura Provinsi Papua. Kajian dilakukan pada bulan Agustus sampai Desember 2017. Metode pendekatan yang digunakan adalah on-farm dan off-farm dengan dengan introduksi varitas unggul baru jagung hibrida yang bersumber dari Balitseral Maros Sulawesi Selatan. Pendekatan on-farm yaitu usaha budidaya kegiatannya pengolahan tanah, tanam, pemeliharaan, panen dan prosesing. Sedangkan off-farm yaitu mengumpulkan data sekunder kegiatannya karakeristik Wilayah, karakeristik petani, harga sarana prasaran (pestisida, pupuk, benih).

\section{Metode Pengumpulan Data}

Metode pengumpulan data dengan pengamatan langsung, observasi, wawancara, dan demarea seluas 4 ha dengan perlakuan varietas hibrida bima 19 URI, Bima 20 URI, Nasa-29 dan Bisi2 luasan masing-masing 1 ha dengan menggunakan 4 petani kooperator. Jenis data yang di kumpulkan yaitu biaya usahatani meliputi pembukaan/pembersihan lahan, persiapan dan pengolahan lahan, penanaman hingga panen dan pasca panen. Data kuantitatif, sedangkan Metode analisis kuantitatif dari inovasi teknologi yang diintroduksi mengunakan 6 (lima) pendekatan analisis yaitu a) analisis pendapatan, b) analisis $\mathrm{R} / \mathrm{C}$ rasio, c) analisis $\mathrm{B} / \mathrm{C}$ rasio, d) titik impas/BEP, e) analisis imbalan kerja dan $f$ ) efisiensi tenaga kerja dapat dijabarkan sebagai berikut :

\section{a. Analisis pendapatan}

Untuk menganalisis pendapatan usahatani jagung menggunakan analisis imbangan penerimaan dan biaya atau $\mathrm{R} / \mathrm{C}$ rasio. Pendapatan usahatani dianalisis berdasarkan struktur penerimaan dengan pembiayaan usahataniAnalisis pendapatan diperoleh dengan menghitung selisih antara penerimaan dengan biaya produksi, (Soekartawi 2003), rumus yang digunakan adalah :

$\mathrm{Pd}=\mathrm{TR}-\mathrm{TC}$ 
Keterangan:

$\mathrm{Pd}=$ Pendapatan usahatani

$\mathrm{TR}=($ total revenue $)$ Total penerimaan

$\mathrm{TC}=($ total cost $)$ Total biaya

\section{b. Analisis Return Cost Ratio (R/C)}

Indikator kelayakan usahatani dianalisis berdasarkan rasio penerimaan (revenue) atas biaya (cost) (Soekartawi, 2006), dengan rumus:

$\mathrm{R} / \mathrm{C}=$ Revenue $/$ Cost $($ Penerimaan/Biaya $) \ldots$ (2)

Penerimaan = Q.PQ

Biaya $\quad=$ TVC

Keterangan:

$\mathrm{Q} \quad=$ produksi jagung (ton pipilan kering)

$\mathrm{PQ}=$ harga jual jagung $(\mathrm{Rp} / \mathrm{kg})$

$\mathrm{TVC}=$ total variabel cost / biaya total input produksi (Rp)

Jika nilai :

1. $\mathrm{R} / \mathrm{C}>1$, maka usahatani jagung tersebut menguntungkan.

2. $\mathrm{R} / \mathrm{C}<1$, maka usahatani jagung tersebut tidak menguntungkan atau rugi.

3. $\mathrm{R} / \mathrm{C}=1$, maka usahatani jagung tersebut berada pada titik pulang atau titik impas yaitu total cost sama dengan total Reveune

\section{c. Analisis Benefit Cost Ratio (B/C)}

Benefit cost ratio adalah ukuran perbandingan antara pendapatan (Benefit $=\mathrm{B}$ ) dengan Total Biaya produksi $($ Cost $=\mathrm{C})$. Dalam batasan besaran nilai $\mathrm{B} / \mathrm{C}$ dapat diketahui apakah suatu usaha menguntungkan atau tidak menguntungkan dengan (Hendayana, 2016), rumus:

$\mathrm{B} / \mathrm{C}$ ratio $=\mathrm{TB} / \mathrm{TC}$

Keterangan :

$\mathrm{TB}=$ Jumlah Pendapatan

$\mathrm{TC}=$ Total Biaya Produksi

Jika nilai :

$\mathrm{B} / \mathrm{C}$ ratio $\geq 1=$ usaha layak dilaksanakan

$\mathrm{B} / \mathrm{C}$ ratio $<1=$ usaha tidak layak atau merugi

\section{d. Break Even Point (BEP)}

BEP merupakan titik impas karena suatu usaha tidak memperoleh keuntungan dan tidak pula rugi (Suratiyah, 2006). Dalam Pengkajian ini BEP yang akan dianalisis adalah BEP penerimaan, BEP harga dan BEP produksi, dengan rumus :

BEP Penerimaan $(\mathrm{Rp})=\frac{\mathrm{FC}}{1-\frac{\mathrm{VC}}{\mathrm{S}}}$
BEP Produksi $(\mathrm{kg})=\frac{\mathrm{FC}}{\mathrm{P}-\mathrm{AVC}}$

$\operatorname{BEP}$ harga $(\mathrm{Rp} / \mathrm{kg})=\frac{\mathrm{TC}}{\mathrm{Y}}$

Dimana :

FC (biaya tetap) = biaya sewa lahan, pajak lahan,biaya bunga, dan penyusutan per usahatani dengan satuan Rp.

$\mathrm{VC}($ biaya variabel $)=$ biaya habis pakai sekali produksi

$\mathrm{TC}($ biaya total $) \quad=$ jumlah biaya variabel dan biaya tetap satuan Rp.

AVC (biaya = total biaya variabel

variabel per unit) dibagi total produksi satuan $\mathrm{Rp} / \mathrm{kg}$

$\mathrm{S}$ (penerimaan) $\quad=$ jumlah produksi dikalikan harga produksi satuan Rp.

$\mathrm{P}($ harga produksi $)=$ harga produksi per unit $\mathrm{Rp} / \mathrm{kg}$

$\mathrm{Y}($ produksi total $) \quad=$ jumlah produksi per usahatani satuan $\mathrm{kg}$

BEP penerimaan, BEP harga dan BEP produksi dianalisis untuk mengetahui pada tingkat berapa harga dan produksi berapa usaha mengalami titik impas. Analisis break even point (analisis balik modal) digunakan untuk menentukan seperti pernyataan (Hendayana, 2016) bahwa (1) jumlah penjualan minimun yang harus dipertahankan agar perusahaan tidak mengalami kerugian, jumlah penjualan minimun ini berarti juga jumlah produksi minimun yang harus dibuat. (2) Jumlah penjualan yang harus dicapai untuk memperoleh laba yang telah direncanakan atau dapat diartikan bahwa tingkat produksi harus ditetapkan untuk memperoleh laba tersebut.

\section{e. Analisis Imbalan Kerja (IK)}

Untuk menganalisis IK kita tidak perlu mengumpulkan data secara khusus akan tetapi 
dapat memanfaatkan data struktur pebiayaan dan pendapatan usahatani. Imbalan kerja petani dapat diperoleh dengan cara membagai pendapatan dengan jumlah curahan kerja. Secara matematis dapat dirumuskan (Hendayana, 2016) sebagai berikut:

$$
\mathrm{IK} .=\frac{\left(\mathrm{Q}^{\mathrm{x}} \mathrm{pQ}\right)-\left(\sum \mathrm{Xi}{ }^{\mathrm{x}} \mathrm{pXi}\right)+\mathrm{FC}}{\sum \mathrm{HOK}}
$$

$$
\begin{aligned}
& \text { Keterangan : } \\
& \text { IK } \quad=\text { imbalan kerja ( Rp/bulan) } \\
& \mathrm{Q}=\text { jumlah produksi dalam satuan } \\
& (\mathrm{kg}) \\
& \mathrm{pQ} \quad=\text { harga per unit produksi }(\mathrm{Rp} / \mathrm{kg}) \\
& \sum \mathrm{Xi} \quad=\text { jumlah input } \mathrm{X} \text { ke } \mathrm{i} \\
& (\mathrm{i}=1,2,3 \ldots, \mathrm{n}) \\
& \mathrm{pXi} \quad=\text { harga satuan input } \mathrm{X} \text { ke } \mathrm{i}(\mathrm{Rp}) \\
& \sum \mathrm{Xi}^{\mathrm{x}} \mathrm{pXi}=\text { jumlah pengeluaran }(\mathrm{Rp}) \\
& \sum \mathrm{HOK}=\text { jumlah hari orang kerja } \\
& \text { (hari/org) } \\
& \text { FC } \quad=\text { fixel cost (biaya tetap) }
\end{aligned}
$$

Kaidah keputusan :

- Jika IK $\geq$ UMR, dikatakan usahatani itu atraktif atau Layak

- Jika IK < UMR, dikatakan usahatani itu kurang atau tidak atratik atau tidak layak

\section{f. Efisiensi Tenaga Kerja}

Efisensi tenaga kerja atau sering disebut produktivitas tenaga kerja dapat di hitung dengan memperhatikan jumlah produksi, penerimaan per hari, dan luas lahan atau luas usaha (Suratiyah, 2006) dengan rumus. Untuk produktivitas dapat di hitung berdasarkan formula sebagai berikut :

$$
\mathrm{P}=\frac{\mathrm{JP}}{\mathrm{JK} 1}
$$

Sedangkan efesiensi tenga kerja dengan formula sebagai berikut :

$$
\mathrm{ETK}=\frac{\mathrm{L}}{\mathrm{JK} 2}
$$

Keterangan :

$$
\begin{array}{ll}
\mathrm{P} & =\text { produktivitas } \\
\mathrm{JP} & =\text { jumlah produksi per ha } \\
\mathrm{JT} 1 & =\text { jumlah tenaga dicurahkan per ha } \\
\mathrm{JK} 2 & =\text { jumlah tenaga dicurahkan per } \\
\mathrm{ETK} & =\text { hari } \\
\mathrm{L} & =\text { efisiensi tenaga kerja } \\
& \text { luas usahatani }
\end{array}
$$

\section{HASIL DAN PEMBAHASAN}

\section{Karakeristik Wilayah}

Lokasi Pengkajian di Kampung Kartini, Distrik Jagebob Kabupaten Merauke, Papua merupakan wilayah dataran rendah. Luas wilayah Distrik Jagebob 1.364,96 $\mathrm{km}^{2}$ atau 2,92 persen dari luas Kabupaten Merauke. Luas tanam jagung 260 ha, (BPS, Merauke 2017). Memiliki topografi datar dengan ketinggian dari $10-25 \mathrm{~m}$, suhu udara rata-rata $26,92^{\circ} \mathrm{C}$, jumlah hari hujan 194 dan jumlah curah hujan $2.578 \mathrm{~mm}$ (BMKG Merauke, 2017)

Kondisi lahan termasuk tipologi tanah netral $\mathrm{pH}$ 6,1-7,3 liat berdebu, bahan organik cukup tinggi belum melapuk secara sempurna. Di Distrik Jagebok mempunyai musim hujan 5-6 bulan dan 6-7 bulan musim kering atau masuk klasifikasi agroklimat C3 (Oldeman,1975). Pada zona agroklimat $\mathrm{C} 3$, pola tanam yang sesuai adalah padi-padi/palawija. Kegiatan usahatani dilokasi kajian didominasi tanaman pangan dan palawija dengan jumlah penduduk 7.386 jiwa, (BPS Merauke 2017). Ditinjau dari segi aksesibilitas wilayah, lokasi cukup baik dengan tersedianya dukungan sarana dan prasarana transportasi yang memadai, jarak lokasi dengan ibukota pemerintahan kabupaten $90 \mathrm{~km}$.

\section{Karakteristik Petani}

Karakteristik petani responden seperti umur, pendidikan, jumlah anggota keluarga dan luas lahan sangat mempengaruhi petani dalam mengadopsi teknologi baru. Petani responden dilokasi penelitian memiliki umur 25-65 tahun dengan rata-rata 48 tahun. Tingkat pendidikan sekolah dasar (SD) sampai sekolah menengah atas (SMA), namun rata-rata tingkat pendidikan sekolah menengah pertama (SMP). Petani berada pada kisaran umur produktif sehingga penerapan inovasi teknologi yang diaplikasikan diharapkan lebih mudah diterima dan diadopsi. Selain itu mereka juga memiliki jumlah anggota lebih banyak dengan luas lahan garapan lebih besar. Menurut Somarmo et al. (2009) kepemilikan lahan sempit, mendorong berkembangnya sistem penyakap oleh pemilik lahan petani tanpa lahan. Asih (2009) mengemukakan bahwa pada umur muda dengan tingkat pendidikan tinggi memungkinkan petani lebih dinamis dan menerima inovasi baru. Identifikasi petani 
responden di lahan kering kabupaten Merauke dapat dilihat pada Tabel 1.

Tabel 1. Identifikasi petani responden di lahan kering kabupaten Merauke Papua

\begin{tabular}{lcc}
\hline Identitas Responden & Rata-rata & Kisaran \\
\hline Umur (tahun) & 48 & $25-65$ \\
Pendidikan (tahun) & 9 & $0-12$ \\
Anggota Keluarga (orang) & 6 & $1-9$ \\
Luas Lahan (ha) & 3 & $1-5$ \\
Stasus lahan (ha) & & \\
- Miliki (ha) & 3 & 2 \\
- Penyakap (ha) & 2 & 2 \\
- Sewa (ha) & 2 & 1
\end{tabular}

Keterangan: Pendidikan 0-6 tahun status SD, Pendidikan 7-9 status tahun dan pendidikan 10-12 status SMA

Sumber : Data primer diolah, 2018

\section{Produktivitas Jagung di Kabupaten Merauke}

Selama kurun waktu 10 tahun (2008-2017) komoditas jagung di kabupaten merauke berdasarkan luas panen, produktivitas dan produksi, menunjukan keragaan yang tidak stabil sebagaimana disajikan pada gambar 1.

Pada gambar 1 terlihat bahwa produksi jagung selama 10 tahun terakhir di Kabupaten Merauke mengalami perkembangan yang berfluktuasi. Pada tahun 2008-2017 produksi tertinggi diperoleh pada tahun 2009 yaitu 1.341 ton sementra produksi terendah diperoleh pada tahun 2008 yaitu 333,90 ton. Rata-rata produksi selama 10 tahun yaitu 427,373 ton. Demikian pula produktivitas jagung selama 10 tahun terakhir, produktivitas tertinggi diperoleh pada tahun 2011 yaitu 4,46 t/ha sedangkan produktivitas terendah diperoleh pada tahun 2008 yaitu 2,80 t/ha. Adapun produktivitas rata-rata selama 10 tahun yaitu 3,48 t/ha. Keragaan luas panen dan produksi jagung di kabupaten Merauke disajikan dalam Grafik 1. Menurut Halijah (2010) menyatakan bahwa komponen teknologi yang relative mudah digunakan untuk meningkatkan produktivitas jagung adalah varietas unggul baik komposit atau hibrida. Hal tersebut dapat difasilitasi melalui perbaikan sistem produksi dan distribusi benih, pembentukan penangkar benih berbasis pedesaan dan bimbingan penerapan PTT Jagung. Penerapan PTT jagung diawali dengan pemahaman masalah dan peluang pengembangan sumberdaya setempat, mengumpulkan sumberdaya setempat, mengumpulkan informasi, dan menganalisis masalah, serta menidentifikasi teknologi yang sesuai dengan kebutuhan petani di wilayah setempat.

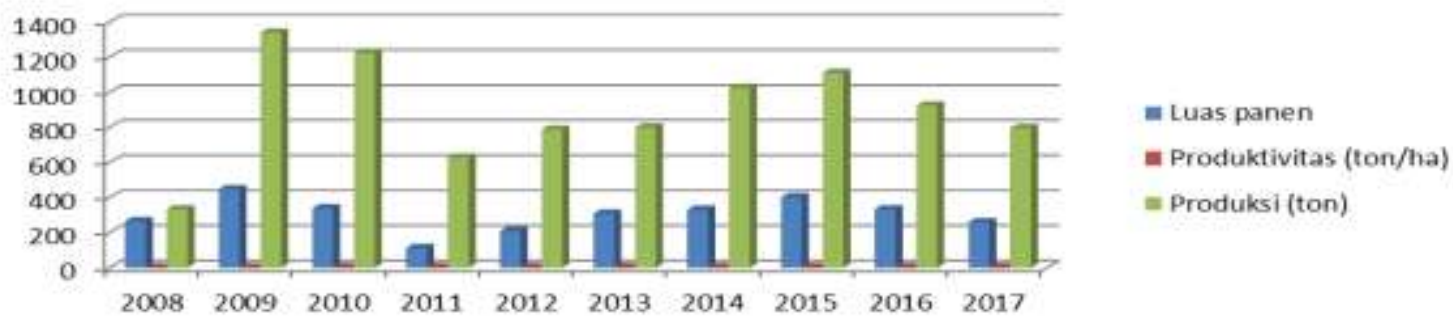

Gambar 1. Luas panen dan produksi jagung di Kab. Merauke 2008 -2017

Tabel 2. Analisis pendapatan usahatani Jagung hibrida pada lahan kering di kabupaten Merauke Papua

\begin{tabular}{lrrrrr}
\hline \multirow{2}{*}{ Uraian } & \multirow{4}{4}{ Satuan } & Varietas \\
\cline { 3 - 6 } & & Bima 19 URI & Bima 20 URI & Nasa 29 & Bisi 2 \\
\hline Produksi & $(\mathrm{Kg} / \mathrm{ha})$ & 5.100 & 7.200 & 7.200 & 6.500 \\
Harga jual & $(\mathrm{Rp})$ & 10.070 .000 & 10.070 .000 & 10.070 .000 & 10.070 .000 \\
Biaya variabel & $(\mathrm{Rp})$ & 895.500 & 895.500 & 895.500 & 895.500 \\
Biaya tetap & $(\mathrm{Rp})$ & 10.966 .500 & 10.966 .500 & 10.966 .500 & 10.966 .500 \\
Total biaya & $(\mathrm{Rp} / \mathrm{ha})$ & 25.500 .000 & 36.000 .000 & 36.000 .000 & 32.500 .000 \\
Penerimaan & $(\mathrm{Rp})$ & 13.904 .500 & 24.404 .500 & 24.404 .500 & 20.904 .500 \\
Pendapatan & & 2.19 & 3.10 & 3.10 & 2.80 \\
R/C & & & & 5.000 \\
\hline Sumberyyyyy
\end{tabular}

Sumber :data primer, 2018 (diolah) 
Uji teknologi di balai penelitian sebelum teknologi dianjurkan biasanya terbatas pada uji keragaan hasil, analisis ekonomi secara umum dan dampaknya terhadap petani (Abdurachman et al., 2006, Makarim et al., 2008)

\section{Analisis Kelayakan Usahatani Jagung Hibrida}

Analisis usahatani dipengaruhi produksi, Biaya usahatani, harga jual dan harga beli sarana produksi yang sangat mempengaruhi pendapatan/keuntungan usahatani. Hasil usahatani pada beberapa jagung hibrida masing-masing mempunyai tingkat produksi yang berbeda varietas bima 19 Uri 5,1 ton/ha sedangkan bima 20 Uri dan Nasa 29 hasil sama 7,2 ton/ha kemudian bisi 2 yakni 6,5 ton/ha. Menurut Aqil dan Arvan (2014) rata-rata hasil jagung varietas unggul antara 5,25 ton/ha sampai 12,3 ton/ha. Pada saat kajian telah memasuki musim kemarau sehingga untuk penyiraman menggunakan mesin alkon pompa air.

Sudiana et al.,2012 menyatakan beberapa keuntungan pemanfaatan lahan pada musim kemarau untuk budidaya jagung, diantaranya hasil cukup tinggi, produktivitas lahan meningkat. Untuk mengetahui besarnya pendapatan, maka terlebih dahulu harus diketahui total dari penerimaan yang diperoleh, kemudian dikurangi dengan total biaya yang telah digunakan dari kegiatan usahatani yang dilakukan. Pendapatan dalam kegiatan usahatani dikatakan menguntungkan apabila penerimaan yang diperoleh lebih besar dari biaya yang dikeluarkan oleh petani. Berikut ini adalah uraian dari biaya produksi, penerimaan, pendapatan dan kelayakan dari usahatani. Hasil analisis pendapatan usahatani jagung hibrida dapat dilihat di Tabel 2.

Pada Tabel 2 terlihat bahwa biaya variabel yang terdiri dari benih, pupuk, pestisida dan tenaga kerja ke empat varietas yaitu Rp 10.070.000/ha, sedangkan biaya tetap antara lain biaya penyusutan alat, sewa mesin, sewa lahan ke empat varietas yaitu Rp $895.500 /$ ha. Total biaya usahatani jagung hibrida dilahan kering Kabupaten Merauke untuk ke empat varietas yaitu Rp 10.966.500/ha per musim. Produksi jagung hibrida bima 19 URI yaitu $5.100 \mathrm{~kg}$ pipil kering dengan harga $\mathrm{Rp} 5.000 / \mathrm{kg}$ diperoleh penerimaan $\mathrm{Rp}$ 25.500.000 maka diperoleh pendapatan $\mathrm{Rp}$
13.904.500 dengan R/C 2,19 atau B/C 1,19. Produksi jagung hibrida bima 20 URI dan Nasa 29 masing-masing $7.200 \mathrm{~kg}$ pipil kering dengan

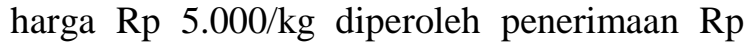
36.000.000 maka diperoleh pendapatan $\mathrm{Rp}$ 24.404.400 dengan R/C 3,10 atau B/C 2,10. Produksi jagung hibrida bisi 2 yaitu $6.500 \mathrm{~kg}$ pipil kering dengan harga $\mathrm{Rp} 5.000 / \mathrm{kg}$ diperoleh penerimaan $\mathrm{Rp} 32.000 .000$ maka diperoleh pendapatan $\mathrm{Rp} 20.904 .500$ dengan $\mathrm{R} / \mathrm{C} 2,80$ atau $\mathrm{B} / \mathrm{C} 1,80$.

Jika dilihat dari total penerimaan, alokasi biaya usahatani hanya menghabiskan $\mathrm{Rp}$ 10.966.500/ha dari total penerimaan artinya bawa masih lebih banyak menerima imbalan dari usahatani yaitu Rp 25.500.000. Dengan memperhitungkan antara penerimaan dan biaya produksi maka usahatani jagunghibrida bima 19 URI cukup layak dikembangkan dengan imbangan R/C 2,19 artinya bahwa setiap pengeluaran biaya sebesar Rp 1.000 terhadap input yang diberikan akan memperoleh penerimaan sebesar Rp 2.190. Sedangkan bima 20 URI dan Nasa 29 sangat layak dikembangkan dimana setiap pengeluaran $\mathrm{Rp}$ 1.000 terhadap input yang di keluarkan memperoleh keuntungan sebesar Rp 3100 dan bisi 2 memperoleh keuntungan Rp 2.800 .

Produksi jagung ditentukan oleh penggunaan input-inputnya baik benih, pupuk, pestisida dan tenaga kerja dan sistem tanam. Menurut Boediono (1990) menyatakan bahwa, biaya mencakup suatu pengukuran nilai sumber daya yang harus dikorbankan sebagai akibat dari aktivitas-aktivitas yang bertujuan untuk mencari keuntungan.

\section{Analisis Penerimaan Impas, Produksi Impas dan Harga Impas}

Analisis TIP (titik impas produksi), dan TIP (titk impas harga) dalam usahatani tanaman jagung hibrida dilahan kering dilakukan untuk mengetahui hubungan yang terjadi antara biaya usahatani, penerimaan dan volume produksi hasil.Titik impas produksi dan harga secara matematis merupakan titik perpotongan antara penerimaan dengan total biaya saat keuntungan yang diperoleh sama dengan nol. Perpotongan ini menggambarkan tingkat produksi dan harga minimal yang harus diterima untuk mengembalikan modal usahatani. Dengan kata lain total penerimaan nilainya sama dengan nilai total biaya. 
Fransiskus P., Herman M., Siska T.: Analisis Kelayakan Usahatani ...

Tabel 3. Analisis titik impas penerimaan, titik impas produksi dan titik impas harga pada varietas unggul baru jagung hibrida di lahan kering Kabupaten Merauke.

\begin{tabular}{clrrrr}
\hline No. & Uraian & Bima 19 Uri & Bima 20 URI & Nasa 29 & Bisi 2 \\
\hline 1. & Total biaya (Rp) & 11.595 .500 & 11.595 .500 & 11.595 .500 & 11.595 .500 \\
2. & Produksi (Kg) & 5.100 & 7.200 & 7.200 & 6.500 \\
3. & Harga (Rp/kg) & 5.000 & 5.000 & 5.000 & 5.000 \\
4. & Titik Impas Peneriman (Rp) & 1.468 .032 & 3.198 .214 & 3.198 .214 & 1.297 .536 \\
5. & Titik Impas Produksi Kg/ha) & 296 & 249 & 249 & 260 \\
6. & Titik Impas Harga (Rp/Kg) & 2.273 & 1.610 & 1.610 & 1.783 \\
\hline
\end{tabular}

Sumber : Data primer, 2019 (diolah)

Tabel 4. Analisis imbalan kerja, efisiensi tenaga kerja pada budidaya varietas unggul baru jagung hibrida di lahan kering Kabupaten Merauke.

\begin{tabular}{clrrrr}
\hline No. & Uraian & Bima 19 URI & Bima 20 URI & Nasa 29 & Bisi 2 \\
\hline 1. & Produksi (Kg) & 5.100 & 7.200 & 7.200 & 6.500 \\
2. & Penerimaan (Rp/ha) & 25.500 .000 & 36.000 .000 & 36.000 .000 & 32.500 .000 \\
3. & Total biaya (Rp) & 11.595 .500 & 11.595 .500 & 11.595 .500 & 11.595 .500 \\
4. & Tenaga Kerja (HKO) & 58 & 58 & 58 & 58 \\
5. & Imbalan kerja (Rp/hari) & 239.233 & 420.767 & 420.767 & 360.422 \\
6. & Produktivitas (Kg/JKO) & 88 & 124 & 124 & 112 \\
7. & Efisiensi tenaga kerja & & & 6,2 & 6,2 \\
\hline
\end{tabular}

Sumber : Data primer, 2019 (diolah)

Hasil analisis titik impas penerimaan, titik impas produksi dan titik impas harga dapat disajikan dalam Tabel 3. Untuk titik impas keempat varietas jagung hibrida yang di introduksikan tampak mengalami keuntungan yang sangat signifikan. Dimana jagung bima 19 URI diperoleh penerimaan sebesar Rp 1.468 .032 per musim per usahatani, produksi $296 \mathrm{~kg} / \mathrm{ha}$ dengan harga jual $\mathrm{Rp} 2.273 / \mathrm{kg}$. Kemudian bima 20 URI dan Nasa 29 mendapatkan titik impas yang sama penerimaan di peroleh sebesar Rp.3.198.214 per musim per usahatani, produksi $249 \mathrm{~kg} / \mathrm{ha}$, atau dengan harga jual $\mathrm{Rp} 1.610 \quad / \mathrm{kg}$. Sedangkan jagung bisi 2 untuk titik impas penerimaan Rp 1.297.536 per musim per usahatani, produksi $260 \mathrm{~kg} / \mathrm{ha}$, atau harga jual $\mathrm{Rp} 1.783 / \mathrm{kg}$.

\section{Analisis Imbalan Kerja, Efisensi Tenaga Kerja}

Analisis imbalan kerja dapat memberikan gambaran informasi mengenai usahatani apakah layak untuk dilanjutkan atau beralih ke profesi lain yang memberikan keuntungan. Untuk mengetahui imbalan kerja yang di hasilkan memberikan keuntungan dalam usahatani berdasarkan upah minimun regional (UMR) yang berlaku di daerah tersebut.
Imbalan Kerja (IK) mengandung arti "balas Jasa" dari input tenaga kerja. Pada kegiatan usahatani mencerminkan perolehan pendapatan usahatani per orang per satuan waktu tertentu sebagai dampak dari curahan kerja yang diberikan pada kegiatan usahatani tersebut. Pada kegiatan pengkajian ini diasumsikan bahwa dalam satu bulan bekerja selama 30 hari.

Pada Tabel 4. Imbalan kerja yang dihasilkan terhadap ke empat (4) varietas unggul baru jagung hibrida yang di introduksi memberikan nilai masing-masing bima 19 URI Rp 239.233/hari. Jika di hitung per bulan maka imbalan kerja yang diperoleh petani mencapai 30 hari $x$ Rp $239.233=\operatorname{Rp~7.176.990.~Bima~} 20$ URI dan Nasa 29 masing-masing imbalan kerja Rp.420.767/hari untuk per bulan memperoleh 30 hari $\mathrm{x} R \mathrm{Rp} 420.767=\operatorname{Rp} 12.623 .010$. sedangkan jagung bisi 29 imbalan kerja Rp. 360.422/hari. Untuk per bulan mendapatkan imbalan kerja 30 hari $\mathrm{x}$ Rp. $360.422=\mathrm{Rp}$ 10.812.660. Hasil usahatani untuk keempat (4) varietas jagung hibrida memberikan imbalan kerja berfariasi dan relatif sangat tinggi sehingga sangat layak, berdasarkan UMR Papua per bulan Rp 2.895.650. Nilai tertinggi imbalan kerja yakin bima 20 URI dan Nasa 29. 
Tenaga kerja adalah satu unsur penentu, terutama bagi usahatani yang sangat tergantung musim. Menurut Suratiyah, (2012) bahwa karakteristik tenaga kerja bidang usahatani merupakan system-sistem manajerial tertentu yang harus dipahami sebagai usaha peningkatan usahatani itu sendiri. Efisiensi tenaga kerja atau sering disebut produktivitas tenaga kerja dapat di ukur dengan memperhatikan jumlah produksi, penerimaan perhari, dan luas lahan atau luas usaha.

Pada Tabel 3 dari hasil analisis produktivitas tenaga kerja pada usahatani jagung hibrida. Produktivitas tenaga kerja pada Bima 19 URI $88 \mathrm{~kg} / \mathrm{JKO}$, Bima 20 URI dan Nasa 29 masing-masing $124 \mathrm{Kg} / \mathrm{JKO}$ dan Bisi 2 yaitu $112 \mathrm{~kg} / \mathrm{JKO}$. Sedangkan efisiensi tenaga kerja keempat (4) varietas jagung hibrida membutuhkan 6,2 HOK/hari/ha.

\section{KESIMPULAN DAN SARAN}

Berdasarkan hasil analisis beberapa indikator yang digunakan untuk menjawab kelayakan usahatani beberapa varietas jagung hibrida, dapat disimpulkan bahwa usahatani jagung hibrida dilahan kering di Kabupaten Merauke layak dilaksanakan dan menguntungkan, hal ini ditunjukkan dengan nilai $\mathrm{R} / \mathrm{C}$ diatas $>2-3$. Dengan produktivitas tertinggi VUB Bima 20 URI dan Nasa 29. Sedangkan titik impas produksi maupun titik impas harga keempat (4) varietas memberikan keuntungan yang signifikan. Kemudian imbalan kerja yang diperoleh petani dalam usahatani jagung hibrida lebih besar dibandingkan upah mimimun regional daerah perbulannya, sehingga usahatani jagung hibrida sangat layak untuk dilaksanakan.

\section{DAFTAR PUSTAKA}

Agustian, A. 2012. Dinamika Perkembangan Harga dan Analisis Daya Saing Usahatani Jagung di Provinsi Jawa Timur. Prosiding Seminar Nasional Petani dan Pembangunan Pertanian. Pusat Sosial Ekonomi dan Kebijakan Pertanian. Badan Penelitian dan Pengembangan Pertanian. Kementerian Pertanian.
Agustian, A. dan Friyatno, S. 2014. Analisis Dinamika Permintaan atau Konsumsi dan KebijakanPengembangan Produksi Jagung Nasional. Prosiding Seminar Nasional Hari Pangan Sedunia ke-33. Optimalisasi Sumberdaya Lokal Melalui Diversifikasi Pangan Menuju Kemandirian Pangan dan Perbaikan Gizi Masyarakat Menyongsong Masyarakat Ekonomi ASEAN 2015. Pusat Sosial Ekonomi dan Kebijakan Pertanian. Badan Penelitian dan Pengembangan Pertanian. Kementerian Pertanian.

Aqil. M dan Arvan, R.Y. 2014. Deskripsi Varietas unggul Balai Penelitian Tanaman. Maros: Badan Penelitian dan Serealia Pengembangan Pertanian.

Asih, D.N. 2009 Analisis karakteristik dan tingkat pendapatan usahatani bawahan merah di Sulawesi Tengah. Jurnal Agroland, 16 (1), 53-59.

Atman. 2015. Produksi Jagung; Strategi Meningkatkan Produksi Jagung. Yogyakarta: Penerbit Plantaxia.

Badan Pusat Statistik. 2016. Data Luas Panen, Produktivitas, dan Produksi Jagung Tahun 2011-2015. Jakarta: BPS.

Badan Pusat Statistik Merauke. 2017. Merauke dalam Angka: Luas panen, Produktivitas, dan Produksi Jagung di Kabupaten Merauke Tahun 2008-2016. Merauke: BPS Merauke.

Bahtiar, J., Sondakh, A., dan Tenrirawe. 2010. Analisis Usahatani Beberapa Varietas Unggul Baru Jagung Komposit di Sulawesi Utara. Prosiding Pekan Serealia Nasional. Balai Penelitian Tanaman Serealia.

Boediono. 1990. Ekonomi Mikro. Yogyakarta: BPFE.

BKPD (Badan Ketahanan Pangan Daerah) Provinsi Lampung. 2016. Roadmap Diversifikasi Pangan 2011-2015. Bandar Lampung: BKPD Provinsi Lampung. 
Damardjati, D.S., Subandi, K., Kariyasa, Zubachtirodin, S. dan Saenong. 2005. Prospek dan Arah Pengembangan Agribisnis Jagung. Jakarta: Balitbang Pertanian, Departemen Pertanian.

Hendayana. 2016. Analisis Data Pengkajian: Cerdas dan Cermat Menggunakan Alat Analisis Data untuk Karya Tulis Ilmiah. Jakarta: IAAD Press.

Halijah, A.D. 2010. Peningkatan Produksi Jagung Melalui Penerapan Inovasi Pengelolaan Tanaman Terpadu. IPTEK Tanaman Pangan, 5(1), 64-73.

Hosen, N., Hardiyanto, M., Daniel, E. Mawardi, I., Manti, Atman, dan Harmaini. 2013. Model Peningkatan Produksi dan Pendapatan Petani Jagung Ramah Lingkungan dengan Pendekatan Dinamik Sistem di Sumatera Barat. Laporan Akhir BPTP Sumatera Barat. BPTP Sumatera Barat.

Oldeman. 1975. An agro-climate Map of Java. Bogor: Central Research Institute for Agriculture.

Soekartawi, A. 2003. Teori Ekonomi Produksi dengan Pokok Bahasan Analisis Fungsi Cobb Douglas. Jakarta: Raja Grafindo Persada.

Soekartawi, 2010. Analisis Usahatani. Jakarta: Penebar Swadaya.

Soemarno, Kartasamita, U.G., dan Hakim, L. 2010. Pengelolaan Lahan Sawah dan Reorientasi Target Alih Teknologi Usahatani Padi Di Jawa. IPTEK Tanaman Pangan, 5 (2): 126-145.

Suratiyah, K. 2006. Ilmu Usahatani Pengetahuan Terapan tentang Caracara Petani atau Peternak. Jakarta : Panebar Swadaya.
Suratiyah K. 2012. Kecamatan Ngawen Kabupaten Gunungkidul Ditinjau dari Ekonomi Rumah Tangga Petani Tahun 2010-2011. Yogyakarta: Jurusan Sosial Ekonomi Pertanian Fakultas Pertanian Universitas Gadjah Mada.

Sudiana, M.I. dan Martininggsih, N.G.A.G.E. 2012. Penerapan Teknologi Jarak Tanam dan Varietas Jagung Hibrida Berbasis Semi Organik. Jurnal Ngayah, 3 (4): 3443.

Taufik, M., dan Thamrin, M. 2009. Analisis Input-Output Pemupukan Beberapa Varietas Jagung Di Lahan Kering. Jurnal Penelitian Pertanian Tanaman Pangan, 28 (2): 78-82.

Makarim, A.K., Wijono, A D. Pasaribu, Ikhwani dan Kartasasmita, U.G. 2008. Tingkat kesesuaian dan adopsi PTT Padi sawah Hambatan dan Dukungan Kebijakan yang diperlukan. Laporan Penelitian Analisis Kebijakan Tahun 2008. Bogor: Pusat Penelitian dan Pengembangan Tanaman Pangan.

Pusat Data dan Informasi Kementerian Pertanian. 2016. Data Impor Tahun 2006-2015. Jakarta: Kementerian Pertanian.

Puslitbangtan. 2013. Deskripsi Varietas Jagung Edisi 2013. Bogor: PuslitbangtanBalitbangtan.

Wahid, S., Nuraida, Djafar, B., dan Kasirin. 2006. Kajian Paket Pengembangan Jagung Syngenta terhadap Beberapa Varietas Jagung pada Lahan Sawah yang Ditanam Secara Tanpa Olah Tanah Di Jeneponto. Prosiding Seminar Nasional Jagung. Puslitbangtan. 